\title{
Impact of Nitrogen Regimes and Planting Densities on Stem Physiology, Lignin Biosynthesis and Grain Yield in Relation to Lodging Resistance in Winter Wheat (Triticum aestivum L.)
}

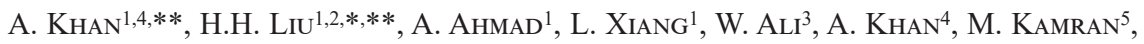 \\ S. AHMAD ${ }^{5}$ and J.C. $\mathrm{LI}^{1,2, *}$ \\ ${ }^{1}$ Anhui Agricultural School of Agronomy University, Hefei, 230036, Anhui, China \\ ${ }^{2}$ Jiangsu Collaborative Innovation Centre for Modern Crop Production, Nanjing 210095, Jiangsu, China \\ ${ }^{3}$ Depatment of Chemistry, Bacha Khan University, Charsadda, Pakistan \\ ${ }^{4}$ Department of Agronomy, Faculty of Crop Production Sciences, The University of Agriculture, \\ Peshawar, Pakistan \\ ${ }^{5}$ College of Agronomy, Northwest A\&F University/Key Laboratory of Crop Physio-ecology and \\ Tillage in Northwestern loess Plateau, Ministry of Agriculture, Yangling, Shaanxi, 712100, China \\ (Received 17 September; Accepted 9 April; \\ Communicated by J. Zhang)
}

Higher plant population and nitrogen management is an adopted approach for improving crop productivity from limited land resources. Moreover, higher plant density and nitrogen regimes may increase the risk of stalk lodging, which is a consequence of complex interplant competition of individual organs. Here, we aimed to investigate the dynamic change in morphology, chemical compositions and lignin promoting enzymes of the second basal internodes altering lodging risk controlled by planting density and nitrogen levels. A field trial was conducted at the Mengcheng research station ( $\left.33^{\circ} 9^{\prime} 44^{\prime \prime} \mathrm{N}, 116^{\circ} 32^{\prime} 56^{\prime \prime} \mathrm{E}\right)$, Huaibei plain, Anhui province, China. A randomized complete block design was adopted, in which four plant densities, i.e., 180, 240, 300, and $360 \times 10^{4} \mathrm{ha}^{-1}$ and four $\mathrm{N}$ levels, i.e., $0,180,240$, and $300 \mathrm{~kg} \mathrm{ha}^{-1}$ were studied. The two popular wheat varieties AnNong0711 and YanNong19 were cultivated. Results revealed that the culm lodging resistance (CLRI) index of the second basal internodes was positively and significantly correlated with light interception, lignin and cellulose content. The lignin and cellulose contents were significantly and positive correlated to light interception. The increased planting density and nitrogen levels declined the lignin and its related enzymes activities. The variety AnNong0711 showed more resistive response to lodging compared to YanNong19. Overall our study found that increased planting densities and nitrogen regimes resulted in poor physical strength and enzymatic activity which enhanced lodging risk in wheat varieties. The current study demonstrated that stem bending strength of the basal internode was significantly positive correlated to grains per spike. The thousand grain weight and grain yield had a positive and significant relationship with stem bending strength of the basal internode. The results suggested that the variety YanNong19 produces higher grain yield $\left(9298 \mathrm{~kg} \mathrm{ha}^{-1}\right)$ at density $240 \times 10^{4} \mathrm{plants} \mathrm{ha}^{-1}$, and $180 \mathrm{~kg} \mathrm{ha}^{-1}$ nitrogen, while AnNong0711 produced higher grain yield (10178.86 $\left.\mathrm{kg} \mathrm{ha}^{-1}\right)$ at density $240 \times 10^{4}$ plants ha ${ }^{-1}$ and with $240 \mathrm{~kg} \mathrm{ha}^{-1}$ nitrogen. Moreover, this combination of nitrogen and planting density enhanced the grain yield with better lodging resistance.

Keywords: winter wheat, lodging, lignin biosynthesis, nitrogen fertilizer, planting density, grain yield

\footnotetext{
*Corresponding authors; E-mails: ljc5122423@126.com, attaboylhh@126.com

**These authors have contributed equally to this work.
}

0133-3720/\$20.00 @ 2019 Akadémiai Kiadó, Budapest 


\section{Introduction}

Wheat (Triticum aestivum L.) is one of the most important cereals available all over the world, and due to its plentiful health benefits it has been in a comparatively higher demand in recent years. In the last half-century, world wheat yield have dramatically increased, primarily as a result of genetic improvement along with improved crop and resource management (Peng et al. 2010b; Fischer 2011). In 2016, the world production of wheat was 749 million tons (FAO), while in $2014,47 \%$ of the global wheat production was achieved by just four countries, of which, China was the leading country. However, it is estimated that food supplies must double in the next few decades to meet the projected demands of the growing population and the increase in consumption (Foley et al. 2011). To meet these challenges, the higher plant population approach has been adopted for improving crop productivity for food security, given the limited land, and nitrogen management is an important field practice for crop growth and yield. However, plant density and nitrogen regimes above certain limit result in poor quality of grains due to lodging in wheat.

Lodging is the structurally permanent displacement of wheat stem from its up-right position. It is one of the most serious problems all over the world, which reduces grain yield by up to $80 \%$ and significantly decreases the quality of bread (Foulkes et al. 2011). A production survey reported that in China losses of about 2 billion $\mathrm{kg}$ in grain occur due to lodging in cereal crops (Zhang et al. 2017a). In the year 1998, 30\% losses were observed in Anhui province, China, due to lodging in wheat (Jin-Cai et al. 2005). It was estimated from this production survey that a reduction of $10-50 \%$ occurs in wheat yield from booting stage to milking stage (Zadoks et al. 2010).

However, scientists have successfully acquainted dwarfing genes to minimize plant height for reducing lodging risk (Allan 1986). The stem diameter, stem wall thickness, and filling degree were positively correlated, while length of basal internodes was negatively correlated with lodging resistance (Tripathi et al. 2003).

Lignin content provides mechanical support to the plant body (Ma 2009). High lignin containing wheat varieties are more resistive to lodging (Sterling et al. 2003).

The nitrogen fertilizer is known to be the major factor that determines grain yield. Under high nitrogen treatment, the crop plant height increased, as it promotes the length and significantly reduces breaking strength of second basal internodes, which cause lodging (Tripathi et al. 2003). Reduction in nitrogen also enhanced stem diameter and wall thickness, which added to the stem strength (Berry et al. 2000). Application of nitrogen up to a certain level increases lignin and cell wall cellulose content of the basal internodes, but beyond that level, simultaneous reduction has also been reported (Wei et al. 2008).

One of the effective ways in boosting the grain yield in wheat crop is increasing planting density. But, at the same time, overly dense plant population may also alter the plant height, length of the basal internodes, thickness of the mechanical tissue, mechanical cell layer and thickness of cortical, which causes severe culm lodging (Feng et al. 2014; Wang et al. 2015b). Planting density beyond the threshold level reduces stem bending strength dry weight per unit length and diameter of the basal internodes, thus resulting in lodging 
(Ling et al. 2007). The relationship between planting density and chemical biosynthesis of the mechanical strength (lignin, cellulose) in regard to lodging is also important. The present study is designed to investigate this particular issue.

Higher levels of nitrogen and planting density causes reduction in lignin content (Wang et al. 2015b). The elevated enzymes activities of phenylalanine ammonia-lyase (PAL), tyrosine ammonialyase (TAL), 4-coumarate: CoA ligase (4CL), and cinnamyl improved the lignin content in plants stem (Boudet et al. 2003). The plant growth and development is mainly affected by light interception and the light itself influences the lignin synthesis (Syros et al. 2005). The accumulated lignin and cellulose content is positive correlated to intercepted light (Ookawa and Ishihara 1993). Lodging strength also varies among different wheat varieties, and the varieties with higher lignin content are more resistant as compared to the variety with lower lignin content (Tripathi et al. 2003).

Previous studies have demonstrated the effect of nitrogenous fertilizer and planting density on stem lodging resistance and wheat yield. The present study was carried out at a critical stage grain filling stage of wheat lodging while specifically considering the second basal internodes. We performed the experiment carefully and faithfully to know the suitable nitrogen level, planting density and also varietal characteristics that are required to withstand the crop against lodging to obtain higher production with better quality. Our results focused on the morphological characteristics of stem basal internodes, index of lodging resistance and the regulation of chemical compositions under four nitrogen levels and four planting densities, which will provide a theoretical base to overcome stalk lodging risk.

\section{Materials and Methods}

\section{Field site}

Experiments were performed during two growing seasons from October to June 20152016 and October to June 2016-2017 at the Anhui Agricultural University Farm, Mengcheng, Anhui Province, China (33 $\left.{ }^{\circ} 44^{\prime \prime} \mathrm{N}, 116^{\circ} 32^{\prime} 56^{\prime \prime} \mathrm{E}\right)$, located in the Huaibei plain. Soil nutrient status in 0-20 cm where the soil type was lime concretion black soil (Shen et al. 2011; Wei et al. 2014) was as follows: The average content of the organic matter in the tillage layer was $12.95 \mathrm{~g} \mathrm{~kg}^{-1}$, total nitrogen was $1.10 \mathrm{~g} \mathrm{~kg}^{-1}$, total phosphorus was $0.78 \mathrm{~g} \mathrm{~kg}^{-1}$, Alkali hydrolysable nitrogen was $68.85 \mathrm{mg} \mathrm{kg}^{-1}$, Effective phosphorus was $19.87 \mathrm{mg} \mathrm{kg}^{-1}$, and effective potassium was $165.67 \mathrm{mg} \mathrm{kg}^{-1}$. Weather conditions during the wheat growing season (Fig. S1*) were close to normal.

\section{Experimental design}

The main plots were treated with two extensive cultivars, AnNong0711 and YanNong19. The subplot contained four plant density levels (180, 240, 300 and 360 plants $\mathrm{m}^{-2}$ ) corresponding to low (D1), medium (D2), high (D3) and highest (D4) density levels, while

*Further details about the Electronic Supplementary Material (ESM) can be found at the end of the article. 
the sub sub-plot with four nitrogen levels $\left(0,180,240,300 \mathrm{~kg} \mathrm{ha}^{-1}\right)$ corresponding to control (N0), low (N1), medium (N2) and high (N3) were established for the field experiment. The experimental plots were arranged in a split-split plot scheme in a completely randomized block design with three replications with a total number of 96 plots. $60 \%$ nitrogen in the form of urea was applied at pre-sowing stage, while $40 \%$ at jointing stage. Each treatment included the use of phosphate fertilizer $\left(\mathrm{P}_{2} \mathrm{O}_{5}\right)$ at the rate of $90 \mathrm{~kg}$ $\mathrm{ha}^{-1}$ and potassium fertilizers (K20) at the rate of $120 \mathrm{~kg} \mathrm{~h}^{-1}$. The plot size was $5 \mathrm{~m} \times 2 \mathrm{~m}$ with 10 rows $(0.2 \mathrm{~m}$ line spacing).

\section{Stem bending strength and culm lodging index}

Stem breaking strength (SBS) was measured at critical periods i.e anthesis, milking and dough stages following the methods of Peng et al. 2014; Chen et al. 2011a, with slightly modifications. Estimation had done using lodging tester machine (Hangzhou TOP Instrument, China). To obtain these measurements first, second and third basal internodes with the stem sheath removed and were placed on the supporting pillars at a distance of $5 \mathrm{~cm}$. The tester was set perpendicular to the middle of the stem, which lodged gradually, and the stem bending strength was measured when the culm internodes was pushed to its breaking point. Stem bending strength was expressed in Newton $(\mathrm{N})$. The methods for culm lodging resistance index (CLRI) measurements are described by Jin-Cai et al. 2005. The culm lodging resistance index was calculated by the formula: Culm lodging resistant index = Culm breaking strength of basal internodes/culm height at center of gravity $\times 100$.

\section{Nitrogen, cellulose, lignin and its enzymes determination}

Cellulose and lignin accumulation during milk stage (DC 72) of wheat at second basal internode was determined on the basis of different nitrogen levels and plant densities. Plant samples were taken from each plot and samples were separated into sheaths and stems, leaves, glumes, and spike rachis and grains. All separated second basal internode samples were oven-dried at $70{ }^{\circ} \mathrm{C}$ to a constant weight to estimate dry matter accumulation. Concentrations of $\mathrm{N}$ were digested $\mathrm{H}_{2} \mathrm{SO}_{4}-\mathrm{H}_{2} \mathrm{O}_{2}$ solution and determined by the Micro-Kjeldahl method (Jones 1987). The stem basal internodes were grinded into powder in liquid nitrogen. The content of cellulose and lignin (mass ratio \%) was measured by procedures used by Updegraff 1969; Zhu et al. 2004. The PAL, TAL, CAD and 4CL were determined by the methods of ASSIS et al. 2001; Wang et al. 2015a.

\section{Determination of light transmittance of canopy}

At every plot from different position the light transmission were investigated at 10 and $60 \mathrm{~cm}$ above the ground. Measurements were done above the ground and light transmission was determined as photosynthetically active radiation (PAR) of the canopy at the full-bloom stage using SUNSCAN machine. 


\section{Yield and yield components}

At maturity the one meter double rows were harvested and sun dried to count the effective spikes. Randomly 30 plants were selected for indoor test to examine the grain number, grain weight.

\section{Data statistical analyses}

The interaction between the wheat cultivars and the data differences in two years overall were non-significant $(\mathrm{P}>0.05)$. The data presented for lodging behaviour were from both years while for stem bending strength, culm lodging resistance index, nitrogen content, cellulose, lignin and its enzymes and yield, mean data of the two years were presented. Analysis of variance was performed with statistix 8.1 and data from each sampling were analyzed separately. Mean data presented were tested by least significant difference at the $\mathrm{P}<0.05$ level $\left(\mathrm{LSD}_{0.05}\right)$. The Pearson's correlations were calculated to identify the relationship of light interception with culm lodging index, lignin and cellulose and culm lodging index with lignin and cellulose content in wheat varieties.

\section{Results}

\section{Planting densities and nitrogen fertilizers Influenced light transmittance} of two wheat varieties

It can be seen from Fig. S2 that canopy light transmission in wheat varieties showed differences with the increase of nitrogen regimes and planting densities. A downward trend was observed for the light transmission with increase of nitrogen levels and planting densities. The light transmission at zero nitrogen was higher than the rest of levels. Similarly PD1 and PD2 absorbed more light compared to PD3 and PD4 because of the over dense plant population. The variety AnNong0711 values for light transmission were higher than for YanNong19 at same nitrogen levels and planting density at the same stage.

As indicated in (Table S1), plant height, culm height center of gravity, internodes length and internodes diameter of both varieties were significantly influenced by nitrogen levels and planting densities. With regard to nitrogen levels, a linear increasing trend was observed and maximum value was recorded with highest level of nitrogen N4 followed by N3, N2 and N0 for all parameters except internodes diameter which showed decreasing trend with further addition of nitrogen. A similar trend of augmented plant height, $\mathrm{CGCH}$ and internodes length was also recorded for planting densities and the maximum value was recorded for D4 followed by D3, D2 and D1. The least internodes diameter was noticed in plots where no nitrogen was applied. Increase in planting density caused a linear decrease in internodes diameter. The AnNong0711 variety had more internodes diameter in comparison to that of YanNong19 variety. YanNong19 variety had a higher plant height, $\mathrm{CGCH}$ and internodes length as compared to AnNong0711 variety. All interactions for all parameters were found significant except $\mathrm{V} \times \mathrm{D}$. 
Analysis of variance showed that first, second and third basal internodes stem bending strength and culm lodging resistance index was significantly affected by nitrogen level, planting densities and varieties at anthesis, milk and dough stages (Tables S2, S3). The planting density and nitrogen interaction was significant for all basal internodes while for second basal internodes the $\mathrm{D} \times \mathrm{N} \times \mathrm{V}$ interaction was also significant at milk stage (Tables S2, S3, Fig. S3). The SBS and CLRI rose and then fell with the increase of nitrogen application rate. Maximum SBS and CLRI of the basal internodes during all three stages were regulated by nitrogen application at the rate of $180 \mathrm{~kg} \mathrm{ha}^{-1}$ while the minimum was recorded at zero nitrogen level. The SBS and CLRI of the two wheat cultivars under each planting density was the largest during the milking period and decreased as the wheat reaches maturity. The possible reason might be at the milking stage the nutrient regulation became fast to fulfill the requirement of seed filling and also to maintain the stem against lodging. The SBS and CLRI decreased as the planting density increased. The SBS and CLRI of the first basal internode were higher than second and third internode which identified the possibility of lodging at second basal internode increases.

\section{PAL, TAL, 4CL, and CAD results}

The effect of nitrogen regimes and planting densities on the four key enzymes on the biosynthesis of lignin in basal second internode formation was found to be significant for both wheat varieties (Figs S4, S5, S6, S7). The interaction D $\times \mathrm{N}$ at 35 and 45 days was significant for all four enzymes. During the development of the second basal internode the activity of PAL enzyme tends to reduce with augmented planting density and nitrogen rate in both wheat varieties. The TAL and CAD enzymes during basal internode formation showed a peak curve and reached to maximum and then constantly declined and turn down to its minimum value at final stage. The zero nitrogen level (N0) and low planting density (PD1) contributed higher values for all four enzymes while nitrogen level (N3) and planting density (PD4) liberated lower values. The activity of 4CL enzyme was quite different from other enzymes and a bimodal curve was illustrated during second basal internode formation. However higher values of PAL, TAL, CAD and $4 \mathrm{Cl}$ activity were educe by AnNong0711 as compared to YanNong19.

\section{Nitrogen content}

The varietal performance also showed significant $(\mathrm{P} \leq 0.05)$ results for nitrogen content. The variety YanNong19 accumulated more nitrogen compared to AnNong0711 (Table S4). Among internodes the nitrogen content showed an increasing trend for both nitrogen levels and planting densities, i.e nitrogen content of internode 3 was higher than first and second basal internodes. It showed that higher nitrogen content in basal internodes would enhance the chances of lodging in wheat varieties. The interactive effective of nitrogen and variety was significant $(\mathrm{P} \leq 0.05)$ which indicated that nitrogen accumulation varies on varietal performance. 


\section{Lignin and cellulose content \%}

The Lignin and cellulose content of basal internodes was significantly $(\mathrm{P} \leq 0.05)$ affected by nitrogen regimes and planting densities (Table $\mathrm{S} 4$ ). The interactions $\mathrm{D} \times \mathrm{N}$ and $\mathrm{D} \times \mathrm{V} \times \mathrm{N}$ were significant $(\mathrm{P} \leq 0.05)$ for second basal internode while for first and third internode the $\mathrm{D} \times \mathrm{N}$ interaction was significant $(\mathrm{P} \leq 0.05)$. Compared to zero nitrogen the higher nitrogen regimes reduced lignin and cellulose content in basal internodes of the stem in both wheat varieties. The lignin and cellulose content was also reduced by increasing planting densities due to inter plant competition. For lignin and cellulose content the varietal difference was also significant $(\mathrm{P} \leq 0.05)$. Here we noticed that internode first contain more lignin and cellulose content followed by second and third internode.

As shown in Table S5 Analysis of variance showed that effective spikes, spike length, spike weight, grains per spike, thousand grain weight and grain yield of both varieties were significantly affected by nitrogen rate and planting densities. The interaction $\mathrm{D} \times \mathrm{N}$ was significant for all parameters except spike length and weight while for grain yield all the interactions were significant except $\mathrm{N} \times \mathrm{D} \times \mathrm{V}$.

The augmented nitrogen increased the number of grains per spike and declined the thousand grain weight while the planting densities showed a decreasing trend for both parameters. The grain yield first enhanced then decreased with the increase amount of nitrogen fertilizers and planting densities. The varietal difference was also significant. The highest grain yield was observed in AnNong0711.

\section{Discussion}

Previous studies are in support with our findings that higher plant height and basal internode length, beyond threshold level, leads the crop to weaken the bending resistance by altering wall thickness and stem diameter, depending upon variety and density (Stapper and Fischer 1990; Zhang et al. 2017a). Previous findings are in agreement to those of ours who reported that application of nitrogen with higher doses uplifted rice crop length and resulted in lodging (Zhang et al. 2016). The higher culm height center of gravity will leads to lodging risk which is supported by the findings of Niu et al. (2012), who reported that wheat population lodging resistance depends on the center of gravity height and stem bending strength. Earlier studies on rice crop also suggested the same results that higher the culm height center of gravity, more is the lodging risk (Guo-Hui et al. 2013; Zhang et al. 2014). It is obvious from previous studies that second basal internode diameter has a significant role in resisting lodging, and increase in diameter improved lodging resistance in rice (Kawasaki et al. 2006). Evaluation of planting density resulted in a linear decrease in second basal internode diameter and similar results have also been reported by Zheng et al. 2017. Addition of nitrogen beyond a certain limit decreased stem diameter of the second basal internode, thus increasing risk of lodging. These results are in line with those of Zhang et al. 2017a, who also found that internode diameter alters with addition of nitrogen either in rate or ratio. The results of our study are consistent with Tripathi et al. 2003, who reported that the variety with high internodes diameter showed high bending strength as compared to that with low internode diameter. 


\section{Effect of light transmission}

Due to inter and intra-specific competition caused by planting densities and nitrogen, the plants canopy structure changing in the shape of taller plants, fewer, elongated and succulent internodes (Figs S2, S8). In this study we identified that lower planting density could meet the light requirement which as a result enhanced the lodging resistance in wheat which is supported by Xiang et al. (2016). The plant growth and development is mainly affected by light interception and the light itself influences the lignin synthesis (Syros et al. 2005). Under suitable light environment the plants produce higher lignin content which could reduce lodging and increases grain yield (Zheng et al. 2017). Here in our results we found that accumulated lignin and cellulose content is significantly and positive correlated to intercepted light which also confirms the findings of Ookawa and Ishihara (1993). It is suggested that adequate nitrogen fertilizers and planting density would capture more light and fulfill its light requirement which would be beneficial to reduce the internodes elongation and improve the mechanical strength of stem

\section{PAL, TAL, 4CL, and CAD enzymes}

The PAL, TAL, 4CL, and CAD enzymes are the main responsible for lignin synthesis (Vanholme et al. 2008). These enzymes contribute mainly in the synthesis of lignin which regulates bending strength of cereals (Khan et al. 2003). PAL enzyme reduces the rate of shikimic acid pathway. The conversion of L-phenylalanine dehydrogenase into trans cinnamic acid is also regulated by the catalytic activity of PAL (Sewalt et al. 1997). The catalytic activity of TAL enzyme found to be more pronounced in cereals which control the conversion of tyrosine into coumaric acid (Rösler and Schmid 1997). The conversion of cinnamic acid into its respective esters, being catalysed by the enzyme 4CL (Lee et al. 1997). Correlation analysis of our study indicated that intercepted light were positively and significantly correlated with lignin content of wheat stalk. The lignin content and the activity of PAL, TAL, 4CL, and CAD decreased with increase of planting densities and the same results were obtained by Marchiori et al. (2014). The lignin content assorted significantly among wheat varieties. The variety AnNong0711 showed better resistance to stem bending strength due to higher lignin content and activity of PAL, TAL, 4CL, and CAD than YanNong19 and similar results were observed by Wang et al. (2014).

Therefore AnNong0711 exist strong ability against lodging. It can be concluded from our findings that higher lignifications may be achieved in case of high activity of PAL, TAL, CAD and 4CL that may lead to improved bending strength against lodging in wheat culms.

\section{Stem bending strength and Culm lodging resistance index}

The lodging resistance index can be used as a measure of lodging resistance in wheat (Jin-Cai et al. 2005). The CLRI rose and then fell from anthesis to maturity, and the maximum value appeared at the grain filling stage and the similar results were obtained 
by Wang et al. (2015b). The CLRI showed quadratic relationship with the addition of nitrogen amount and the same results were observed by Chen et al. (2011b). Our results confirm the finding of Wang et al. (2012), who reported that as the planting densities increased the CLRI values decreased.

Our results are consistent with previous findings of Wang et al. (2015a), who confirmed that the CLRI and stem bending strength showed quadratic relationship with the addition of nitrogen amount. Our results supported by other previous studies (Yang et al. 2009; Jie et al. 2011).

Correlation analysis regarding CLRI and stem bending strength showed significantly positive correlation $\left(\mathrm{r}^{2}=0.9277^{* *}\right)$. We found that the culm lodging index was highly significantly and positive correlated $\left(0.865^{* *}\right)$ to light interception. Increase in nitrogen levels and planting density beyond threshold level would cause to reduce culm lodging resistance index of the second basal internodes and stem bending strength which confirms the findings of Yang et al. (2009); Wei et al. (2008). Our results supported by Li (1996), who reported that dense planting population produced elongated internodes resulted declined the stem mechanical strength and lodging index which induced lodging in wheat. The SBS and CLRI of AnNong0711 was higher than YanNong19 which demonstrated that reduced plant height and moderate amount of nitrogen fertilizer application was beneficial to improve the lodging resistance of wheat stems.

It can be concluded that morphological features reveals best assessment of improved lodging resistance through reduce plant height, increased wall thickness and diameter of wheat.

\section{Nitrogen content $\%$}

Our results are consistent with the findings of Zhang et al. (2017b), who reported that improving nitrogen level showed an upward trend in nitrogen content. Our results supported by Wang et al. (2012), who found that nitrogen content decrease with the increase in density level. The variety YanNong19 was susceptible to lodging and accumulated more nitrogen compared to AnNong0711. Increased nitrogen content in stem basal internodes would enhance lodging risk.

\section{Cellulose content $\%$}

Our results concluded that improved nitrogenous fertilizers and planting densities reduced cellulose and lignin content in both varieties which cause lodging which is supported by Wang et al. (2012); Yaojinbao et al. (2017). Here we investigated that cellulose content had a significantly positive correlation $\left(0.9556^{* *}\right)$ with light interception. The cellulose content of YanNong19 was lower than AnNong0711 which is supported by Crook and Ennos (1995), who reported that cellulose content of different varieties contributed differently to the lodging resistance of wheat stalk and the high amount of cellulose containing stems are more lodging resistive. The variety AnNong0711 was more resistive to lodging and contained more cellulose and lignin content than YanNong19. 


\section{Lignin content \%}

Addition of nitrogen leads to reduce lignin content in second basal internodes of wheat culms which is supported by Wei et al. (2008) who investigated that higher nitrogen content decline lignin content. It is obviously suggested from the results that higher lignin content was obtained from control plots. However further research is needed in this regard. Similar results have been also quoted by Wang et al. (2015b), who confirmed that nitrogen and planting density reduce lignin content in second basal internodes of wheat. The lignin content is highly significant and positive correlated $(0.9422 * *)$ with light interception. AnNong0711 culm basal internodes contained higher amount of lignin content and was more resistive to lodging compared to YanNong19. Our results are in agreement with Chen et al. (2011b), who demonstrated that lignin content also vary among wheat cultivars, and cultivar with low lignin content are more prone to lodging. The increased planting densities decreased the lignin content while low nitrogen level improved the lignin content as well as cellulose content.

Based on our morphological and biochemical results on wheat grain filling stage we assume that over large plant populations and nitrogen regimes influenced the plant growth stages and development which cause a sudden reduction in lignin content and its related enzymes of the culm basal internodes. The lignin content provides stiffness to basal internodes and cellulose content play an important role in reducing lodging risk. It indicated that the first internode augmented more cellulose and lignin content and was more resistive to lodging in both varieties but as these content decreased in the second and third internode the lodging possibility also increased. Overall our experiment indicated that cellulose content could relieve lodging in wheat varieties through the application of suitable amount of nitrogen and planting density. It is demonstrated that the moderately nitrogen level and planting density could an effective way to improve lignin and cellulose content which could reduce the lodging risk in wheat varieties.

The morphological and biochemical work was examined in this study, the other responsible enzymes and genes for lignin biosynthesis should be further taken into account.

\section{Impact of nitrogen and density on yield and its component on winter wheat}

The grain yield of wheat closely related to effective spike per hectare, number of grain number per spike and thousand grain weight (Peng et al. 2010a).

Our results are in agreement with those of Cao et al. (2005), who indicated that the number of effective spikes would not be reason to enhance grain yield because increased number of spikes per hectare resulted in plant competition which resulted poor grain filling and decrease yield. The current study found that the number of effective spikes, grains per spikes and thousand grains weight reduced while the grain yield first increased and then decreased with increase of nitrogen fertilizer which is supported by Yan et al. (2010).

Moderately light intercepted conditions of plants produce higher lignin content which could reduce lodging and increases grain yield of wheat (Zheng et al. 2017). It was observed that increased planting densities reduce grain yield which is supported by Hong- 
Wei (2013). The increase nitrogen fertilizers increased grains per spike while the increased planting density decreased grains per spike (Qiao et al. 2017). The improved planting density and nitrogen cause lodging which had a great impact on yield and yield components. Lodging influenced the thousand kernel weight of both varieties. In our study we find a positive and significant relationship of thousand grain weight and grain yield with stem bending strength. The reduction in lignin content occur due to low irradiance or high planting density, which resulted in reduction of stem bending strength and provide a favorable environment for lodging (Marchiori et al. 2014). Moreover higher planting densities increased inter- and intra-plant competition and the plants were not able to fulfill its photosynthetic requirement in the shape of light, nutrient and water. This scenario may also disturb the translocation of nutrient from root to stem and from stem to grain and finally affected the thousand grain weight and grain yield. The thousand grain weight and grain yield had a positive and significant relationship with stem bending strength of the basal internodes. A suitable nitrogen amount and planting density could improve grain yield and yield components but over dose nitrogen and dense plant population might increase the risk of lodging due to higher inter and intra plant competition which ultimately decrease the grain yield.

To the best of our knowledge we performed, first time carefully studied the lodging risk by the improved planting densities and nitrogen levels, especially the basal internodes morphological impacts on regulating soluble sugar, starch, cellulose, lignin and its related enzymes to enhance lodging resistance in wheat. Therefore in future this work can be considered as a reference study for enhancing lodging resistance in wheat cultivation.

\section{Acknowledgements}

The work is supported by Anhui Agricultural University. We acknowledge financial support by the National Key Research and Development Program of China(2017YFD0300408, 2017YFD0301307).

\section{References}

Allan, R.E. 1986. Agronomic comparisons among wheat lines nearly isogenic for three reduced-height genes. Crop Sci. 26(4):707-710.

Assis, J.S., Maldonado, R. Munoz, T. 2001. Effect of high carbon dioxide concentration on PAL activity and phenolic contents in ripening cherimoya fruit. Postharvest Biol. Tec. 23(1):33-39.

Berry, P.M., Griffin, J.M., Sylvester-Bradley, R. 2000. Controlling plant form through husbandry to minimise lodging in wheat. Field Crop Res. 67(1):59-81.

Boudet, A.M., Kajita, S., Grima-Pettenati, J., Goffner, D. 2003. Lignins and lignocellulosics: a better control of synthesis for new and improved uses. Trends Plant Sci. 8(12):576-581.

Cao, C.F., Lingcong, K., Jianlai, W., Bin, Z., Zhu, Z. 2005. Effects of nitrogen on yield, quality and nutritive absorption of middle and strong gluten wheat. Plant Nutrition \& Fertilizing Science 11(1):46-50.

Chen, X.G., Shi, C.Y., Yin,Y.P. 2011a. Relationship between lignin metabolism and lodging resistance in wheat. Acta Agronomica Sinica 37(9):1616-1622.

Chen, X.G., Shi, Y.H., Wang, C.Y. 2011b. Effects of nitrogen and PP_(333) application on the lignin synthesis of stem in relation to lodging resistance of wheat. Scientia Agricultura Sinica 44(17):3529-3536. 
Crook, M.J., Ennos, A.R. 1995. The effect of nitrogen and growth regulators on stem and root characteristics associated with lodging in two cultivars of winter wheat. J. Exp. Bot. 46(289):931-938.

Feng, H.J., Zhang, S.P., Cun-Jin, M.A. 2014. Effect of plant density on microstructure of stalk vascular bundle of summer maize (Zea mays L.) and its characteristics of sap flow. Acta Agronomica Sinica 40(8):1435.

Fischer, R.A. 2011. Wheat physiology: a review of recent developments. Crop Pasture Sci. 62(2):95-114.

Foley, J.A., Ramankutty, N., Brauman, K.A. 2011. Solutions for a cultivated planet. Nature 478(7369):337.

Foulkes, M.J., Slafer, G.A. Davies, W.J. 2011. Raising yield potential of wheat. III. Optimizing partitioning to grain while maintaining lodging resistance. J. Exp. Bot. 62(2):469.

Li, G.H., Hua, X.Z., Tian, K., Huang, N.R., Pan, J.F., He, T.H. 2013. Effect of nitrogen application on stem lodging resistance of rice and its morphological and mechanical mechanisms. Scientia Agricultura Sinica 46(7):1323-1334.

Hong-Wei, L.U. 2013. Effects of planting density on leaf chlorophyll content and yield of maize. Journal of Anhui Agricultural Sciences.

Li, J., Zhang, H.C., Gong, J.L. 2011. Effects of different planting methods on the culm lodging resistance of super rice. Scientia Agricultura Sinica 44(11):2234-2243.

Li, J.C., Yin, J., Wei, F.Z. 2005. Effects of planting density on characters of culm and culm lodging resistant index in winter wheat. Acta Agronomica Sinica 31(5):662-666.

Jones, J.B. 1987. Nitrogen. Journal Plant Nutr. 10(9-16):1675-1682.

Kawasaki, T., Koita, H., Nakatsubo, T. 2006. Cinnamoyl-CoA reductase, a key enzyme in lignin biosynthesis, is an effector of small GTPase Rac in defense signaling in rice. P. Natl. Acad. Sci. USA. 103(1):230-235.

Khan, W., Prithiviraj, B., Smith, D.L. 2003. Chitosan and chitin oligomers increase phenylalanine ammonialyase and tyrosine ammonia-lyase activities in soybean leaves. J. Plant Physiol. 160(8):859-863.

Lee, D., Meyer, K., Chapple, C., Douglas, C.J. 1997. Antisense suppression of 4-coumarate:coenzyme A ligase activity in Arabidopsis leads to altered lignin subunit composition. Plant Cell 9(11):1985.

Li, J.C. 1996. Effects of cultivars and sowing densities on grain filling characteristics and yield. Journal of Anhui Agricultural University, 4.

Gou, L., Huang, J., Zhang, B., Li, T., Sun, R., Zhao, M. 2007. Effects of population density on stalk lodging resistant mechanism and agronomic characteristics of maize. Acta Agronomica Sinica 40(3):199-204.

Ma, Q.H. 2009. The expression of caffeic acid 3-O-methyltransferase in two wheat genotypes differing in lodging resistance. Jpn. J. Vet. Res. 60(9):2763-2771.

Marchiori, P.E., Machado, E.C., Ribeiro, R.V. 2014. Photosynthetic limitations imposed by self-shading in field-grown sugarcane varieties. Field Crop. Res. 155(1):30-37.

Niu, L., Feng, S., Ru, Z., Li, G., Zhang, Z., Wang, Z. 2012. Rapid determination of single-stalk and population lodging resistance strengths and an assessment of the stem lodging wind speeds for winter wheat. Field Crop. Res. 139(1): $1-8$.

Ookawa, T., Ishihara, K. 1993. Varietal difference of the cell wall components affecting the bending stress of the culm in relation to the lodging resistance in paddy rice. Jpn. J. Vet. Res. 62(3):378-384.

Peng, B., Wang, Y., Li, Y.X. 2010a. Correlation analysis and conditional QTL analysis of grain yield and yield components in maize. Acta Agronomica Sinica 36(10):1624-1633.

Peng, D., Chen, X., Yin, Y. 2014. Lodging resistance of winter wheat (Triticum aestivum L.): Lignin accumulation and its related enzymes activities due to the application of paclobutrazol or gibberellin acid. Field Crop. Res. 157(2):1-7.

Peng, S., Huang, J., Cassman, K.G., Laza, R.C., Visperas, R.M., Khush, G.S. 2010b. The importance of maintenance breeding: a case study of the first miracle rice variety-IR8. Field Crop. Res. 119(2):342-347.

Qiao, W., Zhao, M., Li, H. 2017. Effects of sowing dates and planting densities on yield and yield components of new winter wheat cultivar 'Heng6632'. Chinese Agricultural Science Bulletin 33(2):1-6.

Rösler, J., Schmid, J. 1997. Maize phenylalanine ammonia-lyase has tyrosine ammonia-lyase activity. Plant Physiol. 113(1):175-179.

Sewalt, V.W., Ni, W., Blount, J.W. 1997. Reduced lignin content and altered lignin composition in transgenic tobacco down-regulated in expression of L-phenylalanine ammonia-lyase or cinnamate 4-hydroxylase. Plant Physiol. 115(1):41-50. 
Shen, X., Li, J.C., Qu, H.J., Wei, F.Z., Zhang, Y. 2011. Effects of straw returned to the field on growth and water use efficiency of maize in lime concretion black soil region. Journal of China Agricultural University 16(2):28-33.

Stapper, M., Fischer, R.A. 1990. Genotype, sowing date and plant spacing influence on high-yielding irrigated wheat in southern New South Wales. II. Growth, yield and nitrogen use. Aust. J. Agr. Res. 41(6):1021-1041.

Sterling, M., Baker, C.J., Berry, P.M., Wade, A. 2003. An experimental investigation of the lodging of wheat. Agr. Forest Meteorol. 119(3-4):149-165.

Syros, T.D., Traianos, A.Y., Athanasios, S.E. 2005. Expression of peroxidases during seedling growth in Ebenus Cretica L. as affected by light and temperature treatments. Plant Growth Regul. 46(2):143-151.

Tripathi, S.C., Sayre, K.D., Kaul, J. N., Narang, R.S. 2003. Growth and morphology of spring wheat (Triticum aestivum L.) culms and their association with lodging: effects of genotypes, $\mathrm{N}$ levels and ethephon. Field Crop. Res. 84(3):271-290.

Updegraff, D.M. 1969. Semimicro determination of cellulose in biological materials. Anal. Biochem. 32(3):420-424.

Vanholme, R., Morreel, K., Ralph, J., Boerjan, W. 2008. Lignin engineering. Curr. Opin. Plant Biol. 11(3):278285.

Wang, C., Hu, D., Liu, X. 2015a. Effects of uniconazole on the lignin metabolism and lodging resistance of culm in common buckwheat (Fagopyrum esculentum M.). Field Crop. Res. 180:46-53.

Wang, C., Wu Ruan, R. Hui Yuan, X. 2015b. Effects of nitrogen fertilizer and planting density on the lignin synthesis in the culm in relation to lodging resistance of buckwheat. Plant Prod. Sci. 18(2):218-227.

Wang, C., Shi, Y., Wang, Z., Chen, X., He, M. 2012. Effects of nitrogen application rate and plant density on lodging resistance in winter wheat. Acta Agronomica Sinica 38(1):121-128.

Wei, F.Z., Li, J.C., Wang, C.Y., Qu, H.J., Shen, X.S. 2008. Effects of nitrogenous fertilizer application model on culm lodging resistance in winter wheat. Acta Agronomica Sinica 34(6):1080-1085.

Li, W., Qiao, Y.Q., Chen, H., Cao, C.F., Du, S.Z., Zhao, Z. 2014. Effects of combined straw and N application on the physicochemical properties of lime concretion black soil and crop yields. Acta Ecologica Sinica 34(17)

Xiang, D.B., Zhao, G., Wan, Y., Tan, M.L., Song, C., Song, Y. 2016. Effect of planting density on lodgingrelated morphology, lodging rate, and yield of tartary buckwheat (Fagopyrum tataricum). Plant Prod. Sci. 19(4):1-10.

Fang, Y., Xu, B.C., Turner, N.C., Li, F.M. 2010. Grain yield, dry matter accumulation and remobilization, and root respiration in winter wheat as affected by seeding rate and root pruning. Eur. J. Agron. 33(4):257-266.

Yang, S., Xie, L., Zheng, S., Li, J., Yuan, J. 2009. Effects of nitrogen rate and transplanting density on physical and chemical characteristics and lodging resistance of culms in hybrid rice. Acta Agronomica Sinica 35(1):93-103.

Yao, J., Ma, H., Zhang, P. 2017. Inheritance of stem strength and its correlations with culm morphologi. Can. J. Plant Sci. 91(6):1065-1070.

Zadoks, J.C., Chang, T.T., Konzak, C.F. 2010. A decimal code for the growth stages of cereals. Weed Res. 14(6):415-421.

Zhang, J., Li, G., Song, Y. 2014. Lodging resistance characteristics of high-yielding rice populations. Field Crop. Res. 161(1385):64-74.

Zhang, M., Wang, H., Yi, Y. 2017a. Effect of nitrogen levels and nitrogen ratios on lodging resistance and yield potential of winter wheat (Triticum aestivum L.). Plos One 12(11):e0187543.

Zhang, W., L. Wu, Y. Ding. 2017b. Nitrogen fertilizer application affects lodging resistance by altering secondary cell wall synthesis in japonica rice (Oryza sativa). J. Plant Res. 5:859-871.

Zhang, W., Wu, L., Wu, X. 2016. Lodging resistance of japonica rice (Oryza Sativa L.): morphological and anatomical traits due to top-dressing nitrogen application rates. Rice 9(1):31.

Zheng, M., Chen, J., Shi, Y. 2017. Manipulation of lignin metabolism by plant densities and its relationship with lodging resistance in wheat. Sci. Rep-Uk. 7:41805.

Zhu, L., Shi, G.X., Li, Z.S. 2004. Anatomical and chemical features of high-yield wheat cultivar with reference to its parents. Acta Botanica Sinica 46(5):565-572. 


\section{Electronic Supplementary Material (ESM)}

\section{Electronic Supplementary Material (ESM) associated with this article can be found at the website of CRC at https://akademiai.com/loi/0806}

Electronic Supplementary Table S1. Effect of nitrogen regimes and planting densities on plant height, culm height center of gravity, internode length and internode diameter

Electronic Supplementary Table S2. Effect of nitrogen regimes and planting densities on stem bending strength of wheat varieties

Electronic Supplementary Table S3. Effect of nitrogen regimes and planting densities on CLRI of wheat varieties

Electronic Supplementary Table S4. Effect of nitrogen regimes and planting densities on cellulose and lignin content of two wheat varieties

Electronic Supplementary Table S5. Effect of nitrogen regimes and planting densities on yield and yield components of wheat varieties

Electronic Supplementary Figure S1. Mean temperature and rainfall during the growing seasons in 2015 and 2016

Electronic Supplementary Figure S2. Effect of nitrogen regimes and planting density on canopy light transmittance of wheat varieties. The symbols represents: C1 = AnNong0711, C2 = YanNong19, N0, N1, N2, N3 represents nitrogen regimes while D160-10, D260-10, D360-10, D460-10 represents density level with light transmission at 10 and $60 \mathrm{~cm}$ above ground.Values are means

Electronic Supplementary Figure S3. Represents 3-way interactions, CLRI (a) and starch content (b). The different colors denotes the nitrogen level. The line graphs indicated the mean and standard error of three replications

Electronic Supplementary Figure S4. Effect of nitrogen regimes and planting densities on PAL enzyme activity of lignin synthesis. The different colours denote the days after the second basal internode formation. The lines indicated the means \pm standard error of three replications

Electronic Supplementary Figure S5. Effect of nitrogen regimes and planting densities on TAL enzyme activity of lignin synthesis. The different colours denote the days after the second basal internode formation. The line graphs indicated the means \pm standard error of three replications

Electronic Supplementary Figure S6. Effect of nitrogen regimes and planting densities on CAD enzyme activity of lignin synthesis. The different colours denote the days after the second basal internode formation (a). The line graphs indicated the means \pm standard error of three replications

Electronic Supplementary Figure S7. Effect of nitrogen regimes and planting densities on 4CL enzyme activity of lignin synthesis. The different colours denote the days after the second basal internode formation. The line graphs indicated the means \pm standard error of three replications

Electronic Supplementary Figure S8. The relationship between the light interception with (a), lignin content \%; (b), cellulose content \%; (d), CLRI and (c), lignin content with CLRI; (e), cellulose content with CLRI. (f) Stem bending strength with Grains per spike; (g) Thousand grain weight; (h) Grain yield 